\title{
Single layer centrifugation with androcoll-P prior to freezing enhances the in vitro fertilizing ability of frozen-thawed boar spermatozoa
}

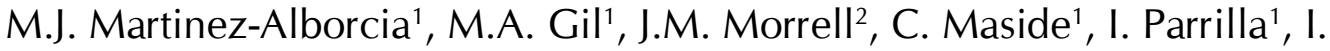 \\ Barranco $^{1}$, J.M. Vazquez ${ }^{1}$, E.A. Martinez ${ }^{1}$ and J. Roca ${ }^{1}$ \\ ${ }^{1}$ Department of Medicine and Animal Surgery, University of Murcia, Spain; ${ }^{2}$ Department of Clinical \\ Sciences, Swedish University of Agricultural Sciences, Sweden
}

Androcoll-P is a species-specific colloid formulated for selecting the most robust sperm population of boar semen samples (Morrell et al. 2009). The colloid formulation differs according to the volume of semen to be processed, which ranges between $15 \mathrm{~mL}$ (Androcoll-P-Large) and $150 \mathrm{~mL}$ (Androcoll-P-XL) (Morrell and Wallgren 2011). The later allows the entire sperm-rich fraction of boar ejaculates to be processed in 3-4 tubes. Single Layer Centrifugation of boar ejaculates prior to freezing with the use of Androcoll-P (SLC-procedure) has proved valuable for improving sperm cryosurvival rates (Martinez-Alborcia et al. 2012). However, SLC-processing also modifies the functionality of cryopreserved spermatozoa, which exhibit lower membrane fluidity and generate less reactive oxygen species than control samples (Martinez-Alborcia et al. 2012). These changes in functionality could influence the fertilizing ability of frozen-thawed (FT) sperm. Elucidation of this matter is mandatory before considering the inclusion of SLCprocedure in routine cryopreservation protocols for boar spermatozoa. The goal of the present experimental study was to evaluate the fertilizing ability under in vitro conditions of FT-sperm from SLC-processed semen samples before freezing by using Androcoll-P-Large (SLC-15) and Androcoll-P-XL (SLC-150).

Thirteen sperm rich ejaculate fractions (one per boar) were split into three aliquots. One aliquot remained unprocessed as a control. The other two aliquots were SLC-processed. For this, the sperm concentration in the diluted sperm-rich fractions was adjusted to $100 \times 10^{6}$ spermatozoa/mL with Beltsville Thawing Solution (BTS). Aliquots of 15 and $150 \mathrm{~mL}$ of semen were layered on the top of $15 \mathrm{~mL}$ and $150 \mathrm{~mL}$ of Androcoll-P-Large (SLC-15) and Androcoll-P-XL (SLC-150) in 50 and $500 \mathrm{~mL}$ tubes, respectively. Following centrifugation at $500 \mathrm{~g}$ for $20 \mathrm{~min}$ at room temperature, the supernatant was removed and the sperm pellet was diluted with BTS $(1: 10, v / v)$ and mixed. Thereafter, semen samples were frozen using a standard $0.5-\mathrm{mL}$ straw protocol (Hernandez et al. 2007). After thawing, FT-sperm samples of the 13 boars (control, SLC-15 and SLC-150) were pooled in order to avoid the individual effect on IVF. The pooled semen samples were purified using PorciPure bottom layer (600 g for $20 \mathrm{~min}$ ). The resulting pellets were washed with BTS (300 $\mathrm{g}$ for $10 \mathrm{~min}$ ), and sperm concentration (NucleocounterSP100, ChemoMetec, A/S) and viability (evaluated by flow cytometry after staining with Hoechst-33342, PI and FITC-PNA) were assessed to calculate the total viable sperm count, in order to inseminate the oocytes with the same number of viable sperm. In vitro matured oocytes $(n=495)$ were inseminated in three replicates with a viable sperm: oocyte ratio of 500:1 and coincubated for $6 \mathrm{~h}$ (Gil et al. 2003). Twelve h later putative zygotes were fixed in $25 \%(\mathrm{v} / \mathrm{v})$ acetic acid in ethanol, stained with $1 \%$ lacmoid in $45 \%(\mathrm{v} / \mathrm{v})$ acetic acid and examined under a phase contrast microscope at 400x magnification. Oocytes were considered fertilized when they had one or more swollen sperm heads and/or male pronucleus and their corresponding sperm tails in the ooplasm, along with two polar bodies. The fertilization parameters evaluated were 
penetration (percentage of the number of oocytes penetrated/total mature oocytes inseminated) and the number of male pronuclei per penetrated oocyte. These parameters were analysed statistically using chi-square and ANOVA, respectively.

Table 1. In vitro fertilization parameters of oocytes inseminated with frozen-thawed spermatozoa from boar semen samples subjected to single layer centrifugation with Androcoll-P-Large (SLC-15) or Androcoll-P-XL (SLC150) prior freezing and of oocytes inseminated with spermatozoa from unprocessed boar seemen (control) .

\begin{tabular}{lccc}
\hline Sample & $\begin{array}{c}\text { Mature oocytes } \\
\text { inseminated (no.) }\end{array}$ & $\begin{array}{c}\text { Penetration } \\
(\%)\end{array}$ & $\begin{array}{c}\text { Male pronuclei in } \\
\text { penetrated oocytes (no.) }\end{array}$ \\
\hline Control & 161 & $86.05 \pm 1.47^{\mathrm{a}}$ & $1.65 \pm 0.05^{\mathrm{a}}$ \\
SLC-15 & 170 & $96.73 \pm 1.44^{\mathrm{b}}$ & $2.56 \pm 0.11^{\mathrm{b}}$ \\
SLC-150 & 164 & $94.54 \pm 1.34^{\mathrm{b}}$ & $2.33 \pm 0.09^{\mathrm{b}}$ \\
\hline
\end{tabular}

$\mathrm{a}, \mathrm{b}$ indicates statistical differences at $P<0.01$

The in vitro fertilizing ability of FT-sperm from SLC-processed semen samples was higher $(P$ $<0.01$ ) than those from control samples, regardless of the Androcoll-P used (-Large or $-\mathrm{XL})$, as evidenced by higher penetration rates together with a larger number of male pronuclei per penetrated oocyte (Table 1). Although a large number of male pronuclei in penetrated oocytes does not reflect the physiological events during in vivo fertilization, it does provide a useful estimation of the number of sperm with high fertilizing ability present in a semen sample (Foxcroft et al. 2008). Consequently, it could be stated that SLC-processing of semen samples before freezing improves the fertilizing ability of FT-boar spermatozoa, at least under in vitro conditions. This improvement could be linked to the aforementioned changes in the functionality of FT-sperm. The low membrane fluidity and the minor generation of reactive oxygen species could indicate that FT-sperm from SLC-processed semen samples could be more resilient than unprocessed sperm to undergo the premature capacitation-like changes associated with cryopreservation. Therefore, it is not too speculative to consider that FT-sperm from SLC-processed semen samples could have a longer functional life-span than those from unprocessed semen samples and hence better fertilizing ability. In conclusion, these results indicate that single layer centrifugation of boar ejaculates prior freezing with the use of the colloid Androcoll-P improves the fertilizing ability of frozen-thawed spermatozoa.

This work was supported by GERM (04543/07), Murcia (Spain) and the Swedish Ministry of Agriculture (31-3389/09).

\section{Reference}

Foxcroft GR, Dyck MK, Ruiz-Sanchez A, Novak S \& Dixon WT 2008 Identifying useable semen. Theriogenology 70 1324-1336.

Gil MA, Abeydeera LR, Day BN, Vazquez JM, Roca J \& Martinez EA 2003 Effect of the volume of medium and number of oocytes during in vitro fertilization on embryo development in pigs. Theriogenology 60 767-776.

Hernandez M, Roca J, Gil MA, Vazquez JM, Martinez EA 2007 Adjustments on the cryopreservation conditions reduces the incidence of boar ejaculates with poor sperm freezability. Theriogenology 67 1436-1445.

Martinez-Alborcia MJ, Morrell JM, Parrilla I, Barranco I, Vazquez JM, Martinez EA \& Roca J 2012 Improvement of boar sperm cryosurvival by using single-layer colloid centrifugation prior freezing. Theriogenology 78 11171125.

Morrell JM, Saravia F, VAN Wienen M, Wallgren M \& Rodriguez-Martinez H 2009 Selection of boar spermatozoa using centrifugation on a glycidoxypropyltrimethoxysilane-coated silica colloid. The Journal of Reproduction and Development $\mathbf{5 5}$ 547-552.

Morrell JM \& Wallgren M 2011 Colloid centrifugation of boar semen. Reproduction in Domestic Animals 46 18-22. 